Research Paper

\title{
Circulating Levels of L1-cell Adhesion Molecule as a Serum Biomarker for Early Detection of Gastric Cancer and Esophagogastric Junction Adenocarcinoma
}

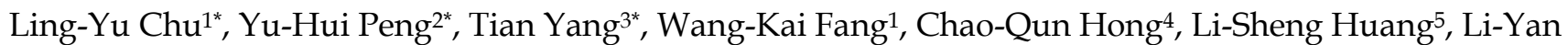

$\mathrm{Xu}^{6}$, En-Min $\mathrm{Li}^{1}$, Yi-Wei Xu ${ }^{{ }^{\bowtie}}$, Jian-Jun Xie ${ }^{1 凶}$

1. Department of Biochemistry and Molecular Biology, Shantou University Medical College, Shantou, China.

2. Department of Clinical Laboratory Medicine, the Cancer Hospital of Shantou University Medical College, Shantou, China.

3. Department of Gastrointestinal Surgery, the First Affiliated Hospital of Shantou University Medical College, Shantou, China.

4. Department of Oncological Laboratory Research, the Cancer Hospital of Shantou University Medical College, Shantou, China.

5. Department of Radiation Oncology, the Cancer Hospital of Shantou University Medical College, Shantou, China.

6. Institute of Oncologic Pathology, Shantou University Medical College, Shantou, China.

*These authors contributed equally to this work.

$\triangle$ Corresponding authors: Department of Biochemistry and Molecular Biology, Shantou University Medical College, No. 22 Xinling Road, Shantou, China. E-mail addresses: g_jjxie@stu.edu.cn (Jian-Jun Xie) or yiwei512@126.com (Yi-Wei Xu).

(C) The author(s). This is an open access article distributed under the terms of the Creative Commons Attribution License (https://creativecommons.org/licenses/by/4.0/). See http://ivyspring.com/terms for full terms and conditions.

Received: 2019.10.11; Accepted: 2020.04.21; Published: 2020.07.11

\begin{abstract}
Background: Low serum L1 cell adhesion molecule (LICAM) has been found in several malignant tumors. Here, we aimed to evaluate the diagnostic potential for serum LICAM in patients with gastric cancers (GC) and esophagogastric junction adenocarcinoma (EJA).

Methods: Enzyme-linked immunosorbent assay (ELISA) was carried out to detect LICAM level in sera of 148 GC patients, 59 EJA patients and 148 healthy controls. Receiver operating characteristics (ROC) was employed to evaluate diagnostic accuracy.

Results: The concentrations of serum LICAM were significantly lower in GC and EJA than those in healthy controls $(P<0.001)$. Detection of LICAM provided a sensitivity of $83.1 \%$, a specificity of $62.2 \%$, and an area under the curve (AUC) of 0.769 (95\% Cl: $0.715-0.823)$ in diagnosing GC, and a sensitivity of $66.1 \%$, a specificity of $62.2 \%$, and an AUC of 0.672 (95\% Cl: $0.590-0.755)$ in diagnosing EJA. Similar results were observed in the diagnosis of early-stage GC $(0.681$ ( $95 \% \mathrm{Cl}: 0.596-0.766))$ and early-stage EJA $(0.674$ (95\% $\mathrm{Cl}: 0.528-0.820)$ ). Analysis of clinical data showed that the levels of LICAM were significantly associated with lymph node metastasis in GC $(P<0.05)$.
\end{abstract}

Conclusions: Our study showed that serum LICAM might be a diagnostic biomarker for GC and EJA.

Key words: gastric cancer, esophagogastric junction cancer, L1CAM, serum biomarker, early diagnosis

\section{Introduction}

Gastric cancers and esophagogastric junction cancers are common digestive tract malignancies all over the world. Gastric cancer is the fifth leading incident cause of cancer and the third leading cause of cancer-related death worldwide. It was estimated that $1,033,701$ new cases were diagnosed as gastric cancer and 782,685 people cases died of it in 2018 [1]. Despite a worldwide decline in the incidence of gastric cancer, incidence of China remains high [1-3]. On the other hand, in the worldwide, the incidence of esophagogastric junctional cancer has increased rapidly in recent decades [1,3]. Some studies have shown that the incidence of esophagogastric junctional cancer in China is higher than that in Western countries $[1,3,4]$. The vast majority of gastric cancers and esophagogastric junctional cancers are adenocarcinomas [5,6]. Despite the use of multimodal treatments such as radical surgery, 
chemotherapy and radiotherapy, gastric cancers (GC) and esophagogastric junction adenocarcinomas (EJA) patients still demonstrate extremely poor survival rate [7-9]. Due to lack of screening strategies for timely diagnosis, many patients are diagnosed with advanced GC and EJA [7-10]. Therefore, early detection of GC and EJA is the key to improve survival rate, and requires an effective screening program.

Currently, the diagnosis of digestive tract tumor relies on endoscopy of symptomatic patients [11]. At present, the diagnostic rate of early-stage GC in China is less than $10.0 \%$, which has gradually increased from recent years, but it is still far lower than the detection rate of $70.0 \%$ in Japan [12]. As endoscopic diagnosis is invasive, very few people are willing to do this examination $[13,14]$. Because the lesions of early-stage GC and EJA are usually relatively small and the changes under endoscopy are relatively subtle, it is difficult to diagnose early-stage GC and EJA by endoscopy. Serological tests are generally considered to be the simplest and the most non-invasive methods for the advantages of allowing high-throughput screening and sample collection. It has been widely developed in clinical diagnosis. However, many of the well-known serum cancer-associated biomarkers, such as carcinoembryonic antigen (CEA), cancer antigen 125 (CA125), cancer antigen 242 (CA242) and cancer antigen 19-9 (CA19-9), are not sensitive and specific enough for screening GC and EJA $[15,16]$. Therefore, we would like to find a better tumor biomarker in this study for early detection of GC and EJA.

L1 cell adhesion molecule (L1CAM), also designated as CD171, is a $200-220-\mathrm{kDa}$ type 1 membrane glycoprotein from immunoglobulin superfamily, known for its roles in nerve cell functions $[17,18]$. L1CAM protein is composed of 1256 amino acids, including extracellular domain, transmembrane domain and intracellular domain. The extracellular portion, consisting of six immunoglobulin domains and five fibronectin repeats (type III), is connected to a small intracellular domain by a transmembrane helix [17,19-21]. In recent years, it has been reported that L1CAM is overexpressed in various types of cancer cells and acts as a driving factor of carcinogenesis [22]. Additionally, L1CAM has been found to be a potential biomarker in several types of human cancers [21,23], including esophageal squamous cell cancer (ESCC) [22], gastrointestinal stromal tumors (GIST) [24], uterine and ovarian cancers [25] and other less common types of cancer. For example, high soluble L1 levels predict poor prognosis of GIST, and may thus be a promising tumor marker that can help to individualized therapy in GIST [24]. Fogel et al. [25] measured the serum L1CAM concentration by ELISA and found it was significantly up-regulated in the serum of ovarian and uterine carcinomas patients compared to the control group. Studies showed that the L1CAM could be used as a biomarker for ovarian and uterine carcinomas associated with poor clinical outcome. However, the diagnostic value of serum L1CAM for GC and EJA has rarely been reported. Therefore, we tried to explore the relationship between serum L1CAM and GC and EJA.

\section{Materials and Methods}

\section{Study samples}

In this study, 148 serum samples of GC patients were collected from the Cancer Hospital of Shantou University Medical College, from June 2012 to November 2016. 59 serum samples of EJA patients were collected from the First Affiliated Hospital of Shantou University Medical College, from January 2018 to November 2018. 148 normal controls were selected from the biobank of Shantou University Medical College, who were healthy subjects with no previous malignant disease enrolled in the Cancer Hospital of Shantou University Medical College and the First Affiliated Hospital of Shantou University Medical College. All the GC and EJA serum samples were collected immediately before any tumor-related treatment and the healthy controls were eligible blood donors with no evidence of cancers. The serum samples were allowed to coagulate at room temperature for 30 mins before centrifuged at 1,250 g for 5 minutes. Then they were stored at a temperature of $-80^{\circ} \mathrm{C}$ until the experiment started.

GC and EJA were diagnosed on the basis of computed tomography or gastroscopy. Tumor stage was defined according to the eighth edition of the American Joint Committee on Cancer (AJCC) Cancer Staging Manual [26]. In the study, we classified tumors with AJCC stage $0+$ I + II as early-stage GC and EJA. The present work was approved by the Ethics Committee of the Cancer Hospital of Shantou University Medical College and the Ethics Committee of the First Affiliated Hospital of Shantou University Medical College and informed to all participants were obtained during blood collection. All work was complied with the principles of the Helsinki Declaration.

\section{Enzyme-Linked Immunosorbent Assay (ELISA) for LICAM}

The levels of Serum L1CAM were detected by ELISA Kit (Sino Biological Inc, cat.no. SEK10140, Beijing, USA). We prepared reagents, samples and 
standard products according to the manufacturer's instructions. Briefly, 96-well ELISA plates (Biohaotian, cat. no. HT081, Jiangsu, China) were coated with 100 $\mu l$ diluted capture antibody $(2 \mu \mathrm{g} / \mathrm{ml})$ and incubated overnight at $4{ }^{\circ} \mathrm{C}$. The plates were washed by microplate washer (Thermo Fisher Scientific), and then blocked using $300 \mu \mathrm{l}$ of blocking buffer and incubated at room temperature for 1 hour. After washing, $100 \mu \mathrm{l}$ of serum samples (a 200-fold dilution) and standards were added in per well and incubated for 2 hours at room temperature. The concentrations of the L1CAM standard curve were $0 \mathrm{pg} / \mathrm{ml}, 47$ $\mathrm{pg} / \mathrm{ml}, 94 \mathrm{pg} / \mathrm{ml}, 188 \mathrm{pg} / \mathrm{ml}, 375 \mathrm{pg} / \mathrm{ml}, 750 \mathrm{pg} / \mathrm{ml}$, $1500 \mathrm{pg} / \mathrm{ml}$, and $3000 \mathrm{pg} / \mathrm{ml}$, respectively. After removing the liquid and washing, $100 \mu \mathrm{l}$ of detection antibody $(0.5 \mu \mathrm{g} / \mathrm{ml})$ was added in per well and incubated for 1 hour at room temperature. Next, after washing, 2001 substrate solution was added to each well and then incubated at room temperature for 20 minutes. Color formation was stopped by stop solution, and the optical density (OD) value was read at wavelength of $450 \mathrm{~nm}$ and $590 \mathrm{~nm}$ on a plate microplate reader (Thermo Fisher Scientific). Use the standard curve method to convert the OD value (Supplementary Table S1) to the concentration and multiply it by the dilution factor. Each serum sample was tested in duplicate and averaged for analysis.

\section{Statistical Analysis}

Data analyses were performed using SPSS (version 19.0), GraphPad Prism 7.0 software and Microsoft Excel. The concentrations of serum L1CAM were obtained with a standard curve. A nonparametric Mann-Whitney's U test was used to compare the difference of serum levels of L1CAM between each group pair. Results were expressed as mean \pm standard deviation. Receiver Operating Characteristic (ROC) curves were plotted and area under the ROC curve (AUC) with 95\% confidence interval (CI) was calculated to analyze the accuracy of diagnostic value. The optimum cut-off values were obtained from the Youden's indexes of the ROC curves, which yield maximum values of sensitivity plus (100\% - specificity) [27]. By using these optimal cutoff values, sensitivity, specificity, positive predictive values (PPV), negative predictive values (NPV), false positive rate (FPR), false negative rate (FNR), positive likelihood ratio (PLR), and negative likelihood ratio (NLR) were calculated. Correlation between clinical parameters and positive rates of serum L1CAM was evaluated with Chi-square test. For all analyses, $P<0.05$ (two-tailed) was considered to be statistically significant.

\section{Results}

\section{The level of serum LICAM in GC, EJA patients and healthy controls}

To evaluate the diagnostic potential of L1CAM, 355 serum samples were tested, including GC patients $(n=148)$, EJA patients $(n=59)$ and healthy control subjects $(n=148)$. The mean age of GC patients, EJA patients and healthy controls in our present study were 58 years, 63 years and 58 years, respectively (Table 1). The levels of L1CAM (mean \pm SD) were $28.687 \pm 14.162 \mathrm{ng} / \mathrm{mL}, 34.506 \pm 19.408 \mathrm{ng} / \mathrm{mL}, 35.265$ $\pm 16.300 \mathrm{ng} / \mathrm{mL}, 33.522 \pm 16.972 \mathrm{ng} / \mathrm{mL}$ and $49.325 \pm$ $31.722 \mathrm{ng} / \mathrm{mL}$ in GC, EJA, early-stage GC, early-stage EJA and healthy control, respectively (Table 2). Compared with normal controls, we noted that L1CAM levels were statistically significantly lower in GC patients, early-stage GC than those in controls (Figure 1A). Similar results were observed in EJA (Figure 1B). However, there was no difference in serum L1CAM between GC and EJA (Supplementary Figure S1).

Table 1. Participant information and clinicopathological characteristics

\begin{tabular}{|c|c|c|c|c|c|}
\hline Group & $\begin{array}{l}\text { GC patients } \\
(\mathrm{n}=148)\end{array}$ & $P^{*}$ & $\begin{array}{l}\text { EJA patients } \\
(\mathrm{n}=59)\end{array}$ & $P^{*}$ & $\begin{array}{l}\text { Normal controls } \\
(\mathrm{n}=148)\end{array}$ \\
\hline \multicolumn{6}{|l|}{ Age (years) } \\
\hline Mean \pm SD & $58 \pm 11$ & 0.899 & $63 \pm 10$ & 0.02 & $58 \pm 11$ \\
\hline Range & $26-81$ & & $22-81$ & & $29-84$ \\
\hline \multicolumn{6}{|l|}{ Gender } \\
\hline Male & 99 & 0.714 & 45 & 0.113 & 96 \\
\hline Female & 49 & & 14 & & 52 \\
\hline \multicolumn{6}{|l|}{ Smoke } \\
\hline Yes & 66 & & 13 & & \\
\hline No & 82 & & 42 & & \\
\hline Unknown & 0 & & 4 & & \\
\hline \multicolumn{6}{|c|}{ Depth of tumor invasion } \\
\hline Tis & 0 & & 2 & & \\
\hline $\mathrm{T} 1$ & 14 & & 3 & & \\
\hline $\mathrm{T} 2$ & 5 & & 2 & & \\
\hline $\mathrm{T} 3$ & 28 & & 2 & & \\
\hline $\mathrm{T} 4$ & 94 & & 40 & & \\
\hline Unknown & 7 & & 10 & & \\
\hline \multicolumn{6}{|c|}{ Lymph node metastasis } \\
\hline No & 43 & & 14 & & \\
\hline N1 & 25 & & 8 & & \\
\hline N2 & 41 & & 7 & & \\
\hline N3 & 31 & & 20 & & \\
\hline Unknown & 8 & & 10 & & \\
\hline \multicolumn{6}{|c|}{ Distant metastasis } \\
\hline Yes & 19 & & 14 & & \\
\hline No & 123 & & 35 & & \\
\hline Unknown & 6 & & 10 & & \\
\hline \multicolumn{6}{|l|}{ TNM stage } \\
\hline 0 & 0 & & 2 & & \\
\hline I & 15 & & 5 & & \\
\hline II & 31 & & 6 & & \\
\hline III & 68 & & 21 & & \\
\hline IV & 31 & & 15 & & \\
\hline Unknown & 3 & & 10 & & \\
\hline
\end{tabular}

${ }^{*}$ Compared with normal controls. GC: Gastric cancers; EJA: Esophagogastric junction adenocarcinomas. 
A

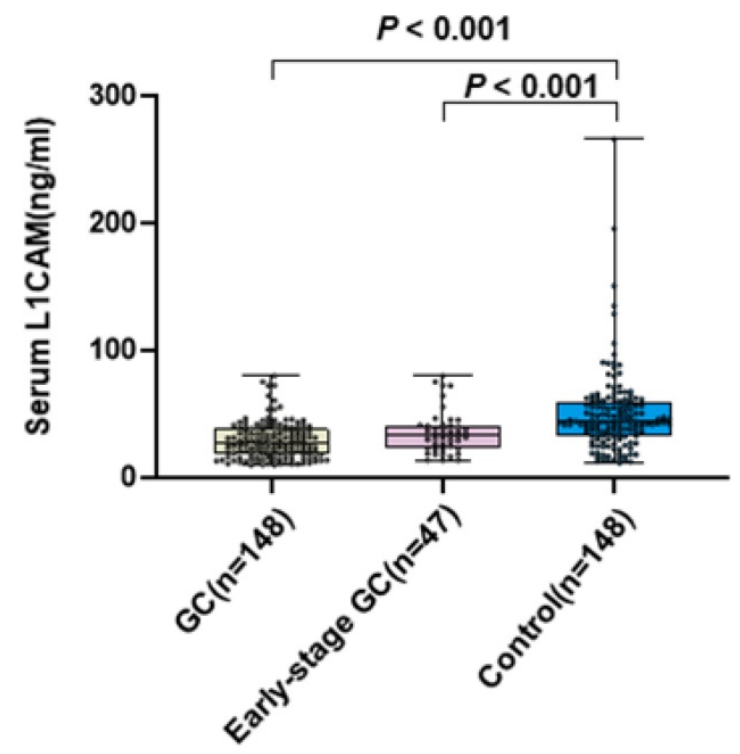

B

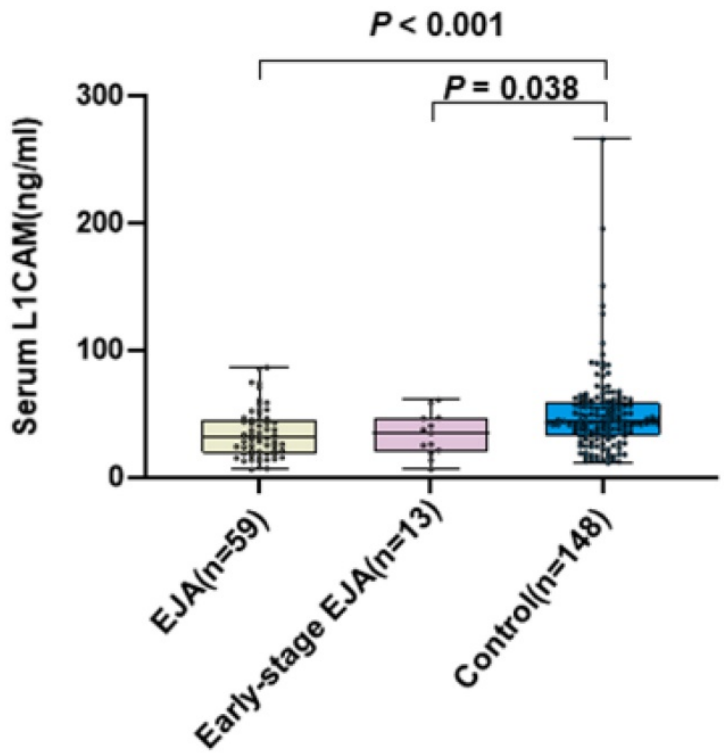

Figure 1. Level of serum LICAM. A. Scatter plot and box plot of OD values of LICAM from GC serum and normal serum. B. Scatter plot and box plot of OD values of LICAM from EJA serum and normal serum. Black horizontal lines are means.

Table 2. Comparison between five groups

\begin{tabular}{|c|c|c|c|}
\hline & $\mathrm{N}$ & Serum L1CAM expression & $P$ value* \\
\hline & & Mean \pm SD & \\
\hline GC & 148 & $28.687 \pm 14.162$ & $<0.001$ \\
\hline Early-stage GC $(0+\mathrm{I}+\mathrm{II})$ & 47 & $35.265 \pm 16.300$ & $<0.001$ \\
\hline Advanced-stage GC (III+IV) & 101 & $25.625 \pm 11.951$ & $<0.001$ \\
\hline EJA & 59 & $34.506 \pm 19.408$ & $<0.001$ \\
\hline Early-stage EJA $(0+\mathrm{I}+\mathrm{II})$ & 13 & $33.522 \pm 16.972$ & 0.038 \\
\hline Advanced-stage EJA (III+IV) & 46 & $34.784 \pm 20.207$ & $<0.001$ \\
\hline Normal controls & 148 & $49.325 \pm 31.722$ & \\
\hline
\end{tabular}

*Compared with normal controls. GC: Gastric cancers; EJA: Esophagogastric junction adenocarcinomas.

\section{Diagnostic capacity of LICAM in all GC and all EJA}

We generated ROC curves to assess diagnostic capacity of serum L1CAM in GC and EJA. According to the ROC curve, the optimized cutoff value for GC and EJA was $40.720 \mathrm{ng} / \mathrm{ml}$. When combined with GC and EJA, we acquired an AUC of 0.742 (95\%CI: $0.689-0.794)$ with a sensitivity/specificity of $78.3 \%$ (95\%CI: 71.9\%-83.6\%) / 62.2\% (95\%CI: 53.8\%-69.9\%). In the early stage, the AUC for L1CAM diagnosis of GC and EJA was 0.679 (95\% CI: 0.601-0.758) and the sensitivity / specificity was $75.0 \%$ (95\% CI: $61.9 \%$ $-84.9 \%$ ) / 62.2\% (95\% CI: $53.8 \%-69.9 \%$ ) (Figure 2A and Table 3). When we analyzed the diagnostic values of serum LICAM in GC and EJA separately, the AUC for GC was 0.769 (95\%CI: 0.715-0.823), and 0.672 (95\%CI: $0.590-0.755)$ for EJA. In the early stage, the AUCs of 0.681 (95\% CI: 0.596-0.766) and 0.674 (95\%CI: 0.528-0.820) were obtained for GC and EJA, respectively (Figure 2 and Table 3). Using a cutoff value of $40.720 \mathrm{ng} / \mathrm{ml}$, the L1CAM has sensitivities of $83.1 \%, 66.1 \%, 76.6 \%$ and $69.2 \%$, has specificities of $62.2 \%, 62.2 \%, 62.2 \%$ and $62.2 \%$ in the GC, EJA, early-stage GC and early-stage EJA patients, respectively (Table 3 ). For better interpretation on clinical value, we performed predictive values and likelihood ratios for L1CAM in the GC and EJA diagnosis, as shown in Table 3.

\section{Correlation between serum concentration of LICAM and clinicopathological features}

The relationships of the levels of serum L1CAM and clinicopathological features were showed in Tables 4 and 5. The levels of L1CAM in GC were significantly associated with lymph node metastasis $(P<0.05)$, but not with other clinical data, including age, gender, smoking, depth of invasion, metastasis and TNM stage (Table 4). However, the levels of L1CAM had no statistical correlation with clinical data of EJA (Table 5). We also used the mean method to analyze the relationship between serum L1CAM concentration and clinicopathological characteristics. The results are shown in supplementary tables S2 and S3.

\section{Discussion}

In recent years, the morbidity and mortality of GC and EJA has ranked among the top in China [2-4]. Helicobacter pylori infection, genetic and environmental factors are high risk factors for GC $[28,29]$. Gastroesophageal refluxes disease (GERD), as well as increasing body weight and obesity, were strongly associated with an increased risk of EJA [4], but associations between $\mathrm{H}$ pylori and EJA are unclear [4,29]. The development of GC includes inflammation, gland atrophy, intestinal metaplasia and dysplasia, and it is considered that the carcinogenic process of EJA is very similar to that of 
GC patients [4,30]. Relevant statistical results showed that the 5-year survival rate of domestic GC patients after surgery was $30.0-50.0 \%$. If early diagnosis can be made, the cancer cells are still confined to the gastric mucosa and submucosa, and the 5-year survival rate can reach to over $90.0 \%[10,15]$. According to the US Cancer Registry, EJA's 5-year survival rate is generally $10.0-15.0 \%$. In early EJA patients, the 5-year survival rate can increase to $25.0-30.0 \%$ [9]. Thus, early diagnosis and early treatment are the key to improving the survival rate of GC and EJA. In recent years, with the in-depth study of clinical medicine, the detection of serum tumor markers has been widely developed in clinical diagnosis. Tumor markers are a class of substances that reflect the presence of tumors. When these substances reach a certain level, they can reveal the existence of certain tumors $[15,16,31]$. This feature makes early diagnosis of GC and EJA possible.

Cell adhesion molecules (CAMs) are cell surface proteins, and they mediate cell-to-cell and/or cell-toextracellular matrix (ECM) interactions [18]. The expression of L1CAM can promote the remodeling of extracellular matrix and enhance the chemotaxis of tumor cells to the extracellular matrix, both of which promote tumor invasion and metastasis [18-20,23]. At present, L1CAM protein has been studied in

A

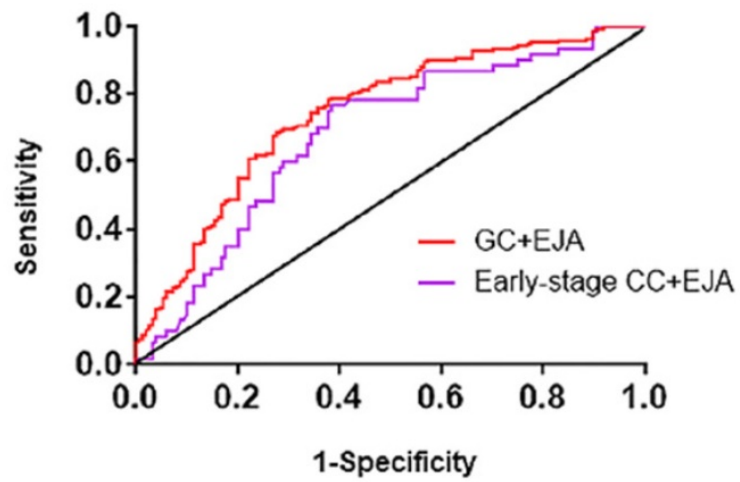

C

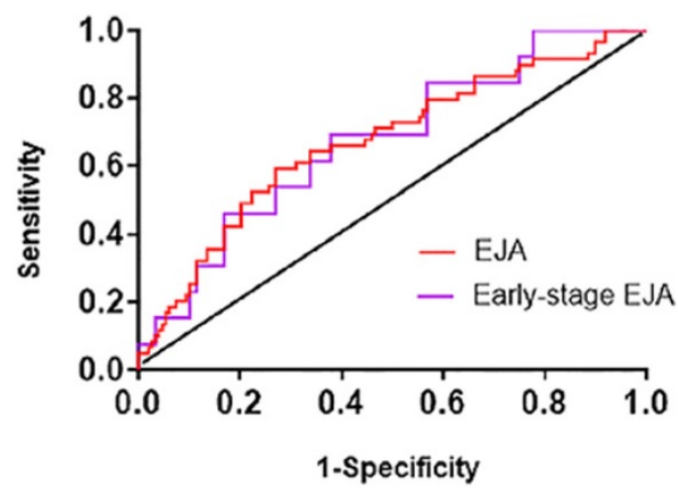

evaluating the malignancy and prognosis of ovarian, endometrial and melanoma tumors $[18,25,32,33]$. The expression of L1CAM protein in cancer tissues and adjacent normal tissues of patients with breast and colorectal cancer was analyzed by immunohistochemical method. The results showed that the expression of L1CAM in cancer tissues was significantly higher than that in adjacent normal tissues [34,35]. These results suggest that L1CAM is involved in the development of tumors. Studies have shown that L1CAM is highly expressed in certain tumor tissues, but not in all tumor tissues, and is limited to certain tumors or subtypes of certain tumors, such as L1CAM is high expression in gastrointestinal stromal tumors (GIST) and uterine and ovarian cancers, but low expression in esophageal squamous cell carcinoma (ESCC) $[22,24,25]$. In our study, the concentrations of serum L1CAM were significantly lower in GC and EJA than those in healthy controls $(P<0.001)$. We speculate that this difference may be due to different expression patterns and different histopathological types of L1CAM in different types of cancer [22]. This has certain significance for differential diagnosis of different tumors. Therefore, L1CAM has broad application prospects as a diagnostic marker for tumors.

B

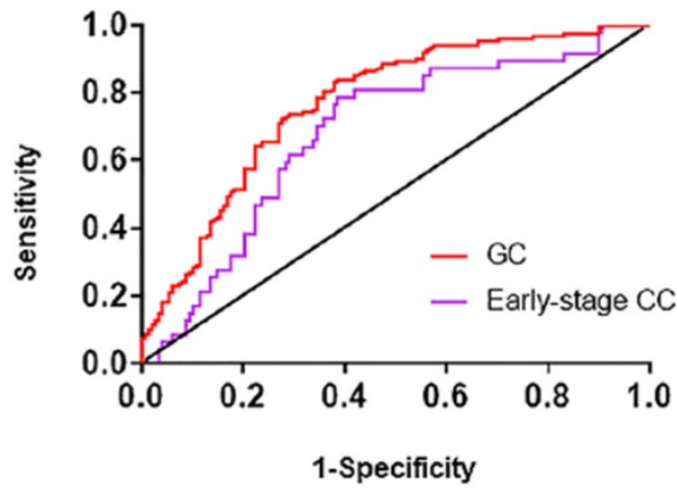

Figure 2. Receiver operating characteristic (ROC) curve analysis in the diagnosis of GC+EJA, GC, EJA, early-stage GC+EJA, early-stage GC and early-stage EJA. A. The ROC curves for serum LICAM in patients with GC+EJA and early-stage GC+EJA compared with those in normal control group. B. The ROC curves for serum LICAM in patients with GC and early-stage GC compared with those in normal control group. C. The ROC curves for serum LICAM in patients with EJA and early-stage EJA compared with those in normal control group. The area under the block line is 0.5 , for reference. 
Table 3. Evaluation of the detection value of LICAM in the diagnosis of GC and EJA

\begin{tabular}{|c|c|c|c|c|c|c|c|c|c|}
\hline Group & AUC (95\%CI) & Sensitivity & Specificity & FPR & FNR & PPV & NPV & PLR & NLR \\
\hline \multicolumn{10}{|l|}{ All-stage } \\
\hline GC vs. NC & $0.769(0.715-0.823)$ & $83.1 \%$ & $62.2 \%$ & $37.8 \%$ & $16.9 \%$ & $68.7 \%$ & $78.6 \%$ & 2.20 & 0.27 \\
\hline EJA vs. NC & $0.672(0.590-0.755)$ & $66.1 \%$ & $62.2 \%$ & $37.8 \%$ & $33.9 \%$ & $41.1 \%$ & $82.1 \%$ & 1.75 & 0.55 \\
\hline GC+EJA vs. NC & $0.742(0.689-0.794)$ & $78.3 \%$ & $64.2 \%$ & $35.8 \%$ & $21.7 \%$ & $74.3 \%$ & $67.2 \%$ & 2.07 & 0.35 \\
\hline \multicolumn{10}{|l|}{ Early-stage } \\
\hline GC vs. NC & $0.681(0.596-0.766)$ & $76.6 \%$ & $62.2 \%$ & $37.8 \%$ & $23.4 \%$ & $39.1 \%$ & $89.3 \%$ & 2.02 & 0.38 \\
\hline EJA vs. NC & $0.674(0.528-0.820)$ & $69.2 \%$ & $62.2 \%$ & $37.8 \%$ & $30.8 \%$ & $13.8 \%$ & $95.8 \%$ & 1.83 & 0.49 \\
\hline GC+EJA vs. NC & $0.679(0.601-0.758)$ & $75.0 \%$ & $62.2 \%$ & $37.8 \%$ & $25.0 \%$ & $44.6 \%$ & $86.0 \%$ & 1.98 & 0.40 \\
\hline
\end{tabular}

AUC, area under the curve; $95 \%$ CI, 95\% confidence interval; GC: gastric cancer; EJA: esophagogastric junctional adenocarcinomas; NC, normal controls; FNR, false negative rate; FPR, false positive rate; PPV, positive predictive value; NPV, negative predictive value; PLR, positive likelihood ratio; NLR, negative likelihood ratio.

Table 4. Association of LICAM level with GC patients' clinicopathologic features

\begin{tabular}{|c|c|c|c|c|}
\hline \multirow[t]{2}{*}{ Variables } & \multicolumn{4}{|c|}{ L1CAM protein } \\
\hline & All cases & Low level & High level & $P$ \\
\hline \multicolumn{5}{|l|}{ Age } \\
\hline$>58$ & 82 & 64 & 18 & \multirow[t]{2}{*}{0.067} \\
\hline$\leq 58$ & 66 & 59 & 7 & \\
\hline \multicolumn{5}{|l|}{ Gender } \\
\hline Male & 99 & 80 & 19 & \multirow[t]{2}{*}{0.288} \\
\hline Female & 49 & 43 & 6 & \\
\hline \multicolumn{5}{|l|}{ Smoke } \\
\hline Yes & 66 & 51 & 15 & \multirow[t]{2}{*}{0.089} \\
\hline No & 82 & 72 & 10 & \\
\hline \multicolumn{5}{|l|}{ Alcohol } \\
\hline Yes & 27 & 21 & 6 & \multirow[t]{2}{*}{0.414} \\
\hline No & 121 & 102 & 19 & \\
\hline \multicolumn{5}{|l|}{ Size of tumor } \\
\hline$>5 \mathrm{~cm}$ & 41 & 37 & 4 & \multirow[t]{3}{*}{0.33} \\
\hline$\leq 5 \mathrm{~cm}$ & 60 & 49 & 11 & \\
\hline Unknown & 47 & 37 & 10 & \\
\hline \multicolumn{5}{|l|}{ Depth of tumor invasion } \\
\hline $\mathrm{T} 1+\mathrm{T} 2$ & 19 & 16 & 3 & \multirow[t]{3}{*}{0.171} \\
\hline $\mathrm{T} 3+\mathrm{T} 4$ & 122 & 103 & 19 & \\
\hline Unknown & 7 & 4 & 3 & \\
\hline \multicolumn{5}{|l|}{ Lymph node metastasis } \\
\hline No & 43 & 33 & 10 & \multirow[t]{5}{*}{0.036} \\
\hline N1 & 25 & 18 & 7 & \\
\hline N2 & 41 & 35 & 6 & \\
\hline N3 & 31 & 31 & 0 & \\
\hline Unknown & 8 & 6 & 2 & \\
\hline \multicolumn{5}{|l|}{ Distant metastasis } \\
\hline Yes & 19 & 16 & 3 & \multirow[t]{3}{*}{0.99} \\
\hline No & 123 & 102 & 21 & \\
\hline Unknown & 6 & 5 & 1 & \\
\hline \multicolumn{5}{|l|}{ TNM stage } \\
\hline Early stage (I+II) & 46 & 35 & 11 & \multirow[t]{3}{*}{0.252} \\
\hline Advanced stage (III+IV) & 99 & 85 & 14 & \\
\hline Unknown & 3 & 3 & 0 & \\
\hline
\end{tabular}

This study demonstrated the potential role of serum L1CAM in the early detection of GC and EJA. Serum L1CAM performed a diagnostic value in GC with AUC of 0.769 , sensitivity of $83.1 \%$ and specificity of $62.2 \%$. As for the EJA, serum L1CAM expression levels demonstrated AUC values of 0.672 , associated with $66.1 \%$ sensitivity and $62.2 \%$ specificity. Similar results were observed in the early-stage GC and early-stage EJA. Combined with GC and EJA, the diagnostic value of AUC was 0.742, the sensitivity was $78.3 \%$ and the specificity was $62.2 \%$. In conclusion, the diagnostic value of serum L1CAM on
GC seems better than that of EJA, which may be due to the fact that the sample size of GC is larger than that of EJA. If the sample size of EJA is increased, the diagnostic value may be improved. In our previous study, serum L1CAM levels were measured by ELISA in 94 normal and 191 ESCC patients, and the results showed that it achieved the AUC of 0.644 for ESCC and 0.629 for early-stage ESCC [22]. These findings suggest that serum L1CAM might be a marker for the diagnosis of gastrointestinal cancer.

Table 5. Association of LICAM level with EJA patients' clinicopathologic features

\begin{tabular}{|c|c|c|c|c|}
\hline \multirow[t]{2}{*}{ Variables } & \multicolumn{4}{|c|}{ L1CAM protein } \\
\hline & All cases & Low level & High level & $P$ \\
\hline \multicolumn{5}{|l|}{ Age } \\
\hline$>63$ & 44 & 31 & 13 & \multirow[t]{2}{*}{0.226} \\
\hline$\leq 63$ & 15 & 8 & 7 & \\
\hline \multicolumn{5}{|l|}{ Gender } \\
\hline Male & 45 & 28 & 17 & \multirow[t]{2}{*}{0.259} \\
\hline Female & 14 & 11 & 3 & \\
\hline \multicolumn{5}{|l|}{ Smoke } \\
\hline Yes & 13 & 7 & 6 & \multirow[t]{3}{*}{0.231} \\
\hline No & 42 & 28 & 14 & \\
\hline Unknown & 4 & 4 & 0 & \\
\hline \multicolumn{5}{|l|}{ Diabetes } \\
\hline Yes & 3 & 1 & 2 & \multirow[t]{3}{*}{0.174} \\
\hline No & 52 & 34 & 18 & \\
\hline Unknown & 4 & 4 & 0 & \\
\hline \multicolumn{5}{|l|}{ Adjuvant therapy } \\
\hline Yes & 23 & 15 & 8 & \multirow[t]{3}{*}{0.962} \\
\hline No & 25 & 17 & 8 & \\
\hline Unknown & 11 & 7 & 4 & \\
\hline \multicolumn{5}{|l|}{ Depth of tumor invasion } \\
\hline Tis & 2 & 2 & 0 & \multirow[t]{4}{*}{0.454} \\
\hline $\mathrm{T} 1+\mathrm{T} 2$ & 5 & 2 & 3 & \\
\hline $\mathrm{T} 3+\mathrm{T} 4$ & 42 & 28 & 14 & \\
\hline Unknown & 10 & 7 & 3 & \\
\hline \multicolumn{5}{|l|}{ Lymph node metastasis } \\
\hline N0 & 14 & 10 & 4 & \multirow[t]{5}{*}{0.95} \\
\hline N1 & 8 & 5 & 3 & \\
\hline N2 & 7 & 5 & 2 & \\
\hline N3 & 20 & 12 & 8 & \\
\hline Unknown & 10 & 7 & 3 & \\
\hline \multicolumn{5}{|l|}{ Distant metastasis } \\
\hline Yes & 14 & 9 & 5 & \multirow[t]{3}{*}{0.956} \\
\hline No & 35 & 23 & 12 & \\
\hline Unknown & 10 & 7 & 3 & \\
\hline \multicolumn{5}{|l|}{ TNM stage } \\
\hline Early stage $(0+\mathrm{I}+\mathrm{II})$ & 13 & 9 & 4 & \multirow[t]{3}{*}{0.903} \\
\hline Advanced stage (III+IV) & 36 & 23 & 13 & \\
\hline Unknown & 10 & 7 & 3 & \\
\hline
\end{tabular}

EJA: esophagogastric junction adenocarcinomas. 
Although L1CAM has been shown to be a useful biomarker in the diagnosis of early GC and EJA, its relatively low specificity may limit its clinical application in screening patients with asymptomatic early GC and EJA. However, single tests of serum L1CAM couldn't meet the requirement of clinical practice. Studies have shown that combined detection of multiple serum proteins would increase the sensitivity or specificity in gastrointestinal tract malignancies compared with a single biomarker. As reported, the combination of cancer antigen (CA724), CEA and CA19-9 can improve the diagnosis of GC, increasing the sensitivity from $47.0 \%$ to $74.0 \%$. These are commonly used as serum tumor markers in GC $[15,36]$. The biomarker CA242 also has a high sensitivity up to $44.0 \%$ in GC [37]. Therefore, one of the limitations of our study is that L1CAM is not used in combination with these common markers to diagnose GC and EJA. Moreover, highly sensitive L1CAM can be used for early diagnosis of GC and EJA, thereby improving the prognosis of GC and EJA. Because the specificity of L1CM is relatively low, we hope that L1CAM could be used as a potential biomarker to combine with some established tumor markers (such as CEA, CA724, CA19-9, CA242) for the diagnosis of GC and EJA. At present, the examination of cancer of the digestive tract mainly depends on endoscopy. If the method of this experiment is combined with endoscopy, the common diagnosis might help to improve the diagnosis rate of early-stage GC and EJA. As for the relationship between serum L1CAM and the clinical data of GC and EJA, we found that the level of serum L1CAM was associated to lymph node metastasis $(P<0.05)$ in GC but there was no statistical difference with EJA. These results suggest that L1CAM may play an important role in lymph node metastasis. It is possible that L1CAM, as a member of cell adhesion molecule family, can promote cancer cell trans endothelial metastasis through receptor-ligand interaction [38]. As the age of cancer cases and healthy controls were not well matched, further study could be conducted with corresponding age. However, our study is single and the sample size is small, which may lead to bias. We believe that the power of our study on evaluating serum L1CAM for GC and EJA will be significantly improved if large sample studies are conducted in multiple institutions.

\section{Conclusion}

In summary, our study provided useful information for the diagnostic value of serum L1CAM in GC or EJA, and demonstrated that serum L1CAM might serve as a potential biomarker for early detection of GC and EJA.

\section{Abbreviations}

GC: gastric cancers; EJA: esophagogastric junction adenocarcinomas; CEA: carcinoembryonic antigen; CA125: cancer antigen 125; CA242: cancer antigen 242; CA742: cancer antigen 742; CA19-9: cancer antigen 19-9; L1CAM: L1 cell adhesion molecule; ESCC: esophageal squamous cell cancer; GIST: gastrointestinal stromal tumors; AJCC: American Joint Committee on Cancer; ELISA: Enzyme-Linked Immunosorbent Assay; OD: optical density; ROC curve: receiver operating characteristic curve; AUC: area under the ROC curve; CI: confidence interval; FPR: false positive rate; FNR: false negative rate; PPV: positive predictive value; NPV: negative predictive value; PLR: positive likelihood ratio; NLR: negative likelihood ratio; GERD: gastroesophageal refluxes disease; CAMs: cell adhesion molecules; ECM: extracellular matrix.

\section{Supplementary Material}

Supplementary figure and tables.

http://www.jcancer.org/v11p5395s1.pdf

\section{Acknowledgements}

This work was supported by grants from the National Natural Science Foundation of China (81871921, 81972801 and 81472342); the Natural Science Foundation of Guangdong Province (2018A030307079 and 2019A1515011873); the Innovative and Strong School Project of Guangdong (2018KTSCX068); and Grant for Key Disciplinary Project of Clinical Medicine under the Guangdong High-level University Development Program.

\section{Competing Interests}

The authors have declared that no competing interest exists.

\section{References}

1. Bray F, Ferlay J, Soerjomataram I, et al. Global cancer statistics 2018: GLOBOCAN estimates of incidence and mortality worldwide for 36 cancers in 185 countries. CA Cancer J Clin. 2018; 68: 394-424.

2. Yang L, Parkin DM, Ferlay J, et al. Estimates of cancer incidence in china for 2000 and projections for 2005. Cancer Epidemiol Biomarkers prev. 2005; 14 : 243-50.

3. Liu K, Yang K, Zhang WH, et al. Changes of esophagogastric junctional adenocarcinoma and gastroesophageal reflux disease among surgical patients during 1988-2012. A Single-institution, High-volume Experience in china. Ann Surg. 2016; 263: 88-95.

4. Urabe M, Ushiku T, Shinozaki-Ushiku A, et al. Adenocarcinoma of the esophagogastric junction and its background mucosal pathology: A comparative analysis according to Siewert classification in a Japanese cohort. Cancer Med. 2018; 7: 5145-54.

5. Laurén P. The two histological main types of gastric carcinoma: diffuse and so-called intestinal-type carcinoma. Acta Pathol Microbiol Scand. 1965; 64: 31-49.

6. Siewert JR, Stein HJ. Classification of adenocarcinoma of the esophagogastric junction. Br J Surg. 1998; 85: 1457-9.

7. Li J, Qin SK, Xu JM, et al. Randomized, double-blind, placebo-controlled phase III trial of apatinib in patients with chemotherapy-refractory advanced or metastatic adenocarcinoma of the stomach or gastroesophageal junction. J Clin Oncol. 2016; 34: 1448-54. 
8. Anderson LA, Tavilla A, Brenner H, et al. Survival for oesophageal, stomach and small intestine cancers in Europe 1999-2007: Results from EUROCARE-5. Eur J Cancer. 2015; 51: 2144-57.

9. Siegel RL, Miller KD, Jemal A. Cancer statistics, 2017. CA Cancer J Clin. 2017; 67: 7-30

10. Seregni E, Ferrari L, Martinetti A, et al. Diagnostic and prognostic tumor markers in the gastrointestinal tract. Semin Surg Oncol. 2001; 20: 147-66.

11. Gaddam S, Edmundowicz SA. Endoscopic tumor diagnosis and treatment. Gastrointest Endosc. 2013; 78: 421-7.

12. Hamashima C, Goto R. Potential capacity of endoscopic screening for gastric cancer in Japan. Cancer Sci. 2017; 108: 101-7.

13. Hosokawa O, Miyanaga T, Kaizaki Y, et al. Decreased death from gastric cancer by endoscopic screening: association with a population-based cancer registry. Scand J Gastroenterol.2008; 43: 1112-5.

14. von Karsa L, Patnick J, Segnan N, et al. European guidelines for quality assurance in colorectal cancer screening and diagnosis: overview and introduction to the full supplement publication. Endoscopy. 2013; 45: 51-9.

15. Chen XZ, Zhang WK, Yang K, et al. Correlation between serum CA724 and gastric cancer: multiple analyses based on Chinese population. Mol Biol Rep. 2012; 39: 9031-9.

16. Perkins G.L, Slater ED, Sanders GK, et al. Serum tumor markers. Am Fam Physician. 2003; 68: 1075-82.

17. Moos M, Tacke R, Scherer H, et al. Neural adhesion molecule L1 as a member of the immunoglobulin superfamily with binding domains similar to fibronectin. Nature. 1988; 334: 701-3.

18. Samatov TR, Wicklein D, Tonevitsky AG. L1CAM: Cell adhesion and more. Prog Histochem Cytochem. 2016; 51: 25-32.

19. Appel F, Holm J, Conscience JF, et al. Several extracellular domains of the neural cell adhesion molecule $\mathrm{Ll}$ are involved in neurite outgrowth and cell body adhesion. J Neurosci. 1993; 13: 4764-75.

20. Hlavin ML, Lemmon V. Molecular structure and functional testing of human L1CAM: an interspecies comparison. Genomics. 1991; 11: 416-23.

21. Gutwein P, Stoeck A, Riedle S, et al. Cleavage of L1 in exosomes and apoptotic membrane vesicles released from ovarian carcinoma cells. Clin Cancer Res. 2005; 11: 2492-501.

22. $\mathrm{Xu} \mathrm{YW,} \mathrm{Hong} \mathrm{CQ,} \mathrm{Wu} \mathrm{ZY,} \mathrm{et} \mathrm{al.} \mathrm{Diagnostic} \mathrm{and} \mathrm{prognostic} \mathrm{value} \mathrm{of} \mathrm{serum}$ L1-cell adhesion in esophageal squamous cell carcinoma. Clin Res Hepatol Gastroenterol. 2018; 42: 597-603.

23. Raveh S, Gavert N, Ben-Ze'ev A. L1 cell adhesion molecule (L1CAM) in invasive tumors. Cancer Lett. 2009; 282: 137-45.

24. Zander $\mathrm{H}$, Rawnaq $\mathrm{T}$, Von Wedemeyer $\mathrm{M}$, et al. Circulating levels of cell adhesion molecule L1 as a prognostic marker in gastrointestinal stromal tumor patients. BMC Cancer. 2011; 11: 1-7.

25. Fogel M, Gutwein P, Mechtersheimer S, et al. L1CAM expression as a predictor of progression and survival in patients with uterine and ovarian carcinomas. The Lancet. 2003; 362: 869-75.

26. Amin MB, Greene FL, Edge SB, et al. The Eighth Edition AJCC Cancer Staging Manual: Continuing to build a bridge from a population-based to a more "personalized" approach to cancer staging. CA Cancer J Clin. 2017; 67: 93-9.

27. Ruopp MD, Perkins NJ, Whitcomb BW, et al. Youden Index and optimal cut-point estimated from observations affected by a lower limit of detection. Biom J. 2008; 50: 419-30.

28. Kusano C, Gotoda T, Ishikawa $\mathrm{H}$, et al. The administrative project of helicobacter pylori infection screening among junior high school students in an area of japan with a high incidence of gastric cancer. Gastric Cancer. 2017; 20: $16-9$

29. Kamangar F, Dawsey SM, Blaser MJ, et al. Opposing risks of gastric cardia and noncardia gastric adenocarcinomas associated with Helicobacter pylori seropositivity. J Natl Cancer Inst. 2006; 98: 1445-52.

30. Mo ML, Li MR, Chen Z, et al. Inhibition of the Wnt palmitoyltransferase porcupine suppresses cell growth and downregulates the Wnt/ $\beta$-catenin pathway in gastric cancer. Oncol Lett. 2013; 5: 1719-923.

31. Rigamonti N, Kadioglu E, Keklikoglou L, et al. Role of angiopoietin-2 in adaptive tumor resistance to VEGF signaling blockade. Cell Rep. 2014; 8: 696-706.

32. Meier F, Busch S, Gast D, et al. The adhesion molecule LI (CD171) promotes melanoma progression. Int J Cancer. 2006; 119: 549-55.

33. Geels YP, Pijnenborg JM, Gordon BB, et al. L1CAM expression is related to non-endometrioid histology, and prognostic for poor outcome in endometrioid endometrial carcinoma. Pathol Oncol Res. 2016; 22: 863-8.

34. Zhang J, Yang F, Ding Y, et al. Overexpression of L1 cell adhesion molecule correlates with aggressive tumor progression of patients with breast Cancer and promotes motility of breast cancer cells. Int J Clin Exp Pathol. 2015; 8: 9240-7.

35. Boo YJ, Park JM, Kim J, et al. LI expression as a marker for poor prognosis, tumor progression, and short survival in patients with colorectal cancer. Ann Surg Oncol. 2007; 14: 1703-11.

36. Carpelan-Holmström M, Louhimo J, Stenman UH, et al. CEA, CA19-9 and CA 72-4 improve the diagnostic accuracy in gastrointestinal cancers. Anticancer Res. 2002; 22: 2311-6.

37. Guadagni F, Roselli M, Amato $\mathrm{T}$, et al. CA72-4 measurement of tumor-associated glycoprotein 72 (TAG-72) as a serum marker in the management of gastric carcinoma. Cancer Res. 1992; 52: 1222-7.

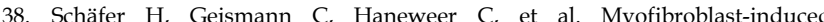
tumorigenicity of pancreatic ductal epithelial cells is L1CAM dependent. Carcinogenesis. 2012; 33: 84-93. 